\title{
Improved protocol for isolation of high-quality total RNA from different organs of Phaseolus vulgaris $\mathrm{L}$.
}

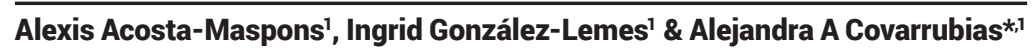

\section{ABSTRACT}

A modified protocol was developed to obtain high-quality total RNA from various mature organs, including leaves, seeds, pods and testae, from different cultivars of Phaseolus vulgaris L. grown under optimal conditions or subjected to severe drought; stress conditions leading to the accumulation of numerous secondary metabolites can affect RNA quality. This modified procedure is based on CTAB extraction protocols. Modifications in this protocol prevent oxidation of phenolic complexes, the precipitation of proteins, DNA and degradation of RNA; also, it is effective at removing secondary metabolites. The RNA obtained following this procedure showed high quality as revealed by a high RNA integrity number and high $260 / 280 \mathrm{~nm}(>2)$ ratio, the requirements needed to increase reliability of diverse molecular analyses.

\section{METHOD SUMMARY}

We describe an improved method to obtain high-quality total RNA from mature organs of Phaseolus vulgaris, a process that usually produces low RNA purity, integrity and quantity. This new protocol allows for successful application in modern molecular biology techniques.

\section{KEYWORDS}

drought $\cdot$ Phaseolus vulgaris L. $\cdot$ RNA integrity number $\cdot$ RNA isolation

${ }^{7}$ Departamento de Biología Molecular de Plantas, Instituto de Biotecnología, Universidad Nacional Autónoma de México (UNAM), Av. Universidad 2001, Cuernavaca, 62210 México; *Author for correspondence: crobles@ibt.unam.mx

BioTechniques 66: 96-98 (February 2019) 10.2144/btn-2018-0129
Common bean (Phaseolus vulgaris L.) is one of the most economically important edible grain-legume worldwide [1], and has been widely used in a variety of physiological and molecular studies. In this context, obtaining high quality (purity, integrity and quantity) total RNA from different organs and developmental stages, is a key element for the successful application of different analytical techniques, including qRT-PCR, microarray and massive sequencing [2]. Many commercial RNA isolation kits are now available [3]; however, they yield satisfactory results only in certain seedlings or plant organs, and often fail when tissues are rich in secondary metabolites, polysaccharides and/or polyphenols. Even though many RNA isolation protocols have been developed for recalcitrant plant species or tissues [4-11], these work successfully only in specific cases, and generally they are time consuming [11]. In common bean, organs such as mature pods, seeds, leaves, flowers, flower buds and testae accumulate numerous and diverse compounds, a circumstance that is even more problematic when plants are subjected to stress. These compounds often interfere with efficient RNA isolation procedures and affect RNA quality (integrity and purity). In this work, we describe an efficient and inexpensive protocol to obtain high-quality RNA from various common bean organs in different developmental stages that overcomes many of the constraints presented by the available procedures.

Modern molecular techniques such as qRT-PCR and massive RNA sequencing demand a high quantity, purity and integrity of total RNA. Usually total RNA from plants is isolated by TRIZOL (Invitrogen, USA) and standard SDS/phenol methods, which are shown to be efficient for a limited variety of plant species, particularly for model systems such as Arabidopsis [12]. Although these limitations have led to the development of alternative protocols and commercial kits, after testing most available procedures these methods did not yield total RNA of sufficiently high quality from most common bean organs. These results prompted us to develop a non-expensive and effective procedure to obtain high-quality total RNA, from different common bean mature organs (leaves, pods, seeds and testae), using two common bean (Phaseolus vulgaris L.) cultivars: Pinto Saltillo and Bayo Madero, varieties characterized as drought-resistant and -sensitive, respectively $[13,14]$. Both cultivars were grown under optimal irrigation in greenhouse conditions at $24 \pm 4^{\circ} \mathrm{C}$ and $65 \pm 5 \%$ relative humidity $(\mathrm{RH})$, until the first flower pods appeared (approximately 25 days). At this point, half of the plants from both cultivars were subjected to severe drought conditions, by watering to $25 \%$ of field capacity [15] during 21 days. The other half was grown under optimal irrigation until the end of the experiment. Samples from mature leaves, empty pods (valves), seeds at mid seed-filling stage (cotyledons and embryos) and testae were collected, frozen immediately in liquid nitrogen, and stored at $-80^{\circ} \mathrm{C}$, until RNA extraction.

In our experience, the TRIZOL method produces a very low-purity RNA with absorbance ratios $260 \mathrm{~nm} / 280 \mathrm{~nm}$ and $260 \mathrm{~nm} / 230 \mathrm{~nm}$ between 0.5 and 1, respectively, particularly out of pods, seeds and testae. The mini hot phenol method [16] was found to produce a brown and waterinsoluble pellet, possibly caused by the formation of insoluble RNA-phenolpolysaccharide complexes [7,17]. We also tested the Quick RNA MiniPrep (Zymo Research, CA, USA) and RNeasy Plant Mini Kit (QiaGen, Hilden, Germany), obtaining sufficiently high quality RNA from leaves; however, the other plant organs produce poor-quality and low-quantity RNA using these kits.

There also appear to be differences in RNA extraction quality between common bean varieties. During the different purifi- 


\section{BioTechniques}

cation attempts, we noticed that the Pinto Saltillo cultivar accumulates more phenolic compounds than Bayo Madero; these compounds might be readily oxidized during the RNA isolation process to potentially form covalently linked quinones [18], which in turn may bind to nucleic acids, hampering the purification procedure.

To overcome the difficulties and disadvantages found in the examined protocols, we resolved to modify the protocol previously reported by Liao et al. [19] for Taxus and Ginkgo, which showed the best performance compared with other methods. To improve the extraction, CTAB concentration was used at $4 \%$ instead of $3 \%$, and the incubation time at $65^{\circ} \mathrm{C}$ was reduced from $10 \mathrm{~min}$ to $1-2 \mathrm{~min}$, to prevent RNA degradation. To avoid sample oxidation polyvinylpyrrolidone (PVP) was replaced with addition of DTT $(25 \mu \mathrm{M})$ and 2-mercaptoethanol (4\%). We found that LiCl precipitation should be performed over 12 to $15 \mathrm{~h}$; shorter periods might lead to lower RNA yields, while longer periods produce the accumulation of unwanted proteins and DNA. For the final precipitation step, absolute ethanol or 2-propanol can be used, in both cases supplemented with an acetate salt to make the process more efficient.

RNA quantity and quality was first assessed by absorbance determination at 260, 280 and $230 \mathrm{~nm}$ (ND-1000 spectrophotometer, NanoDrop Technologies, USA). Absorbance at $260 \mathrm{~nm}$ concerns nucleic acid concentration, whereas at $280 \mathrm{~nm}$ it measures for proteins and at $230 \mathrm{~nm}$ it measures for other possible contaminants such as carbohydrates and phenols [20]. The $260 / 280 \mathrm{~nm}$ ratio is generally used as an indication of the RNA quality (protein contamination), whereas the $260 / 230 \mathrm{~nm}$ ratio denotes its purity (presence of additional contaminants) [2]. The amount of total RNA obtained was between 60 and $200 \mathrm{ng} / \mathrm{mg}$ of tissue, while quality and purity indexes were above two; $260 / 280$ and $260 / 230$ ratios greater than 1.8 are accepted indicators of suitable RNA quality $[21,22]$.

RNA integrity was evaluated using a Bioanalyzer 2100 (Agilent Technologies, USA). In this method RNA samples are electrophoretically separated on a micro-

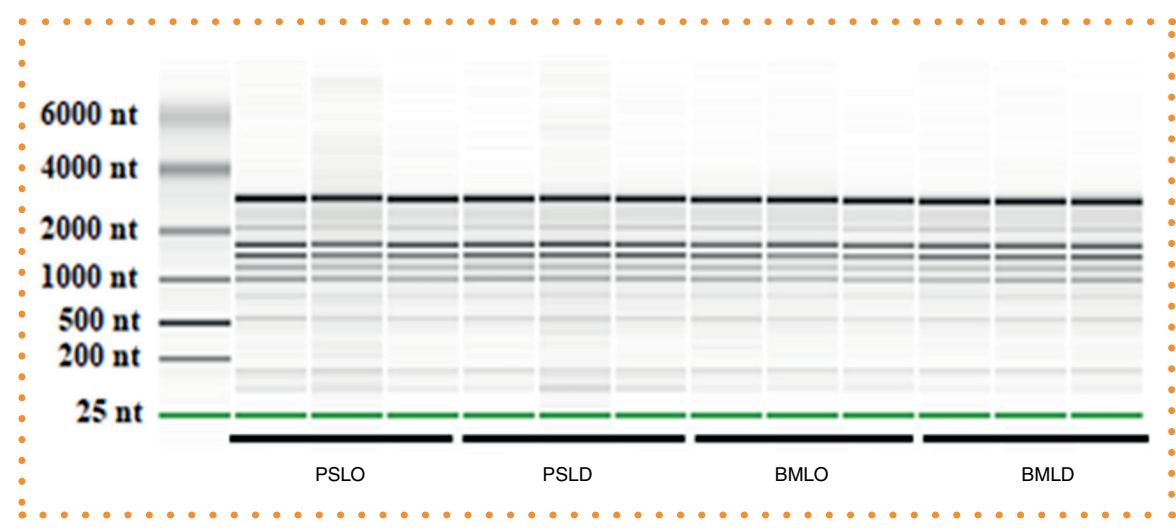

Figure 1. Capillary electrophoretic separation of total RNA extracted from leaves $(\mathrm{L})$ of Pinto Saltillo (PS) and Bayo Madero (BM) plants grown under optimal (O) and drought (D) conditions, using Bioanalyzer 2100. Samples 1-3: PS LO, 4-6: PS LD, 7-9: BM LO and 10-12: BM LD. In addition to the $28 \mathrm{~S}$ and $18 \mathrm{~S}$ RNAs, represented by the more intense bands, samples from leaves also contain RNAs from chloroplasts (16S and 23S) and from mitochondria (23S), corresponding to the fainter bands. The integrity was automatically determined by this equipment as the $28 \mathrm{~S} / 18 \mathrm{~S}$ ratio.

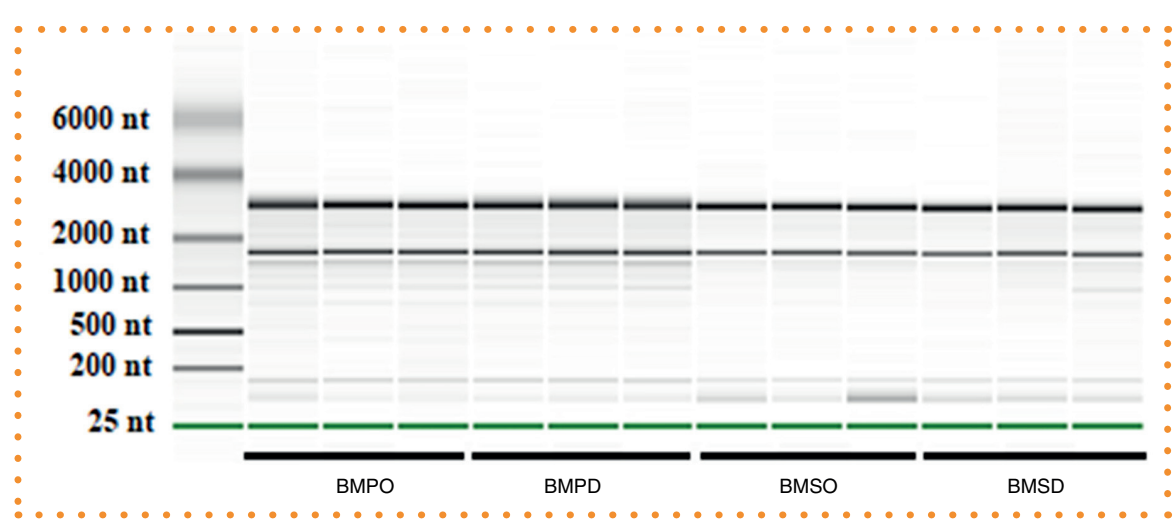

Figure 2. Capillary electrophoretic separation of total RNA from pods $(P)$ and seeds $(S)$ extracted from Bayo Madero (BM) plants grown under optimal (O) and drought (D) conditions, using Bioanalyzer 2100. Samples 1-3: BM PO, 4-6: BM PD, 7-9: BM SO and 10-12: BM SD. Due to the low or absent chloroplast content of these tissues, $28 \mathrm{~S}$ and $18 \mathrm{~S}$ appear as the predominant bands. Similar results were obtained from the Pinto Saltillo cultivar.

fabricated chip and subsequently detected via laser-induced fluorescence detection [2]. Integrity of the RNA may be assessed by quantification of the $18 \mathrm{~S}$ and $28 \mathrm{~S}$ ribosomal RNA bands (Figure 1 and Figure 2).

Additionally, RNA integrity can be evaluated by calculating the score for RNA Integrity Number (RIN) developed by Agilent Technologies [23]. The established algorithm for this allows the classification of total RNA integrity using a numbering system from 1 to 10 , assigning 1 to the most degraded profile and 10 to that with the highest integrity. Fleige and Pfaffl [2] recommend a RIN higher than five to consider the quality of a total RNA sample as good, and a RIN higher than eight for a sample with a 'perfect' total RNA quality. The samples obtained using the method described here reproducibly showed total RNA with average RIN values of 9.2 (Figure $3)$, which correlates with the high integrity of the samples determined by the different parameters.

The application of modern molecular techniques to mature organs of Phaseolus vulgaris $\mathrm{L}$. has frequently been hindered by the difficulty to isolate high-quality RNA. The RNA obtained with this procedure was successfully used in qRT-PCR and massive RNA sequencing, with a quality score $\left(Q_{30}\right)$ of $86 \%$ for Pinto Saltillo and $89 \%$ for Bayo Madero, supporting the results described above. This protocol will help to deepen our understanding and molecular characterization of different common bean RNA and transcriptomic processes, and might be applied to other recalcitrant plant species. 


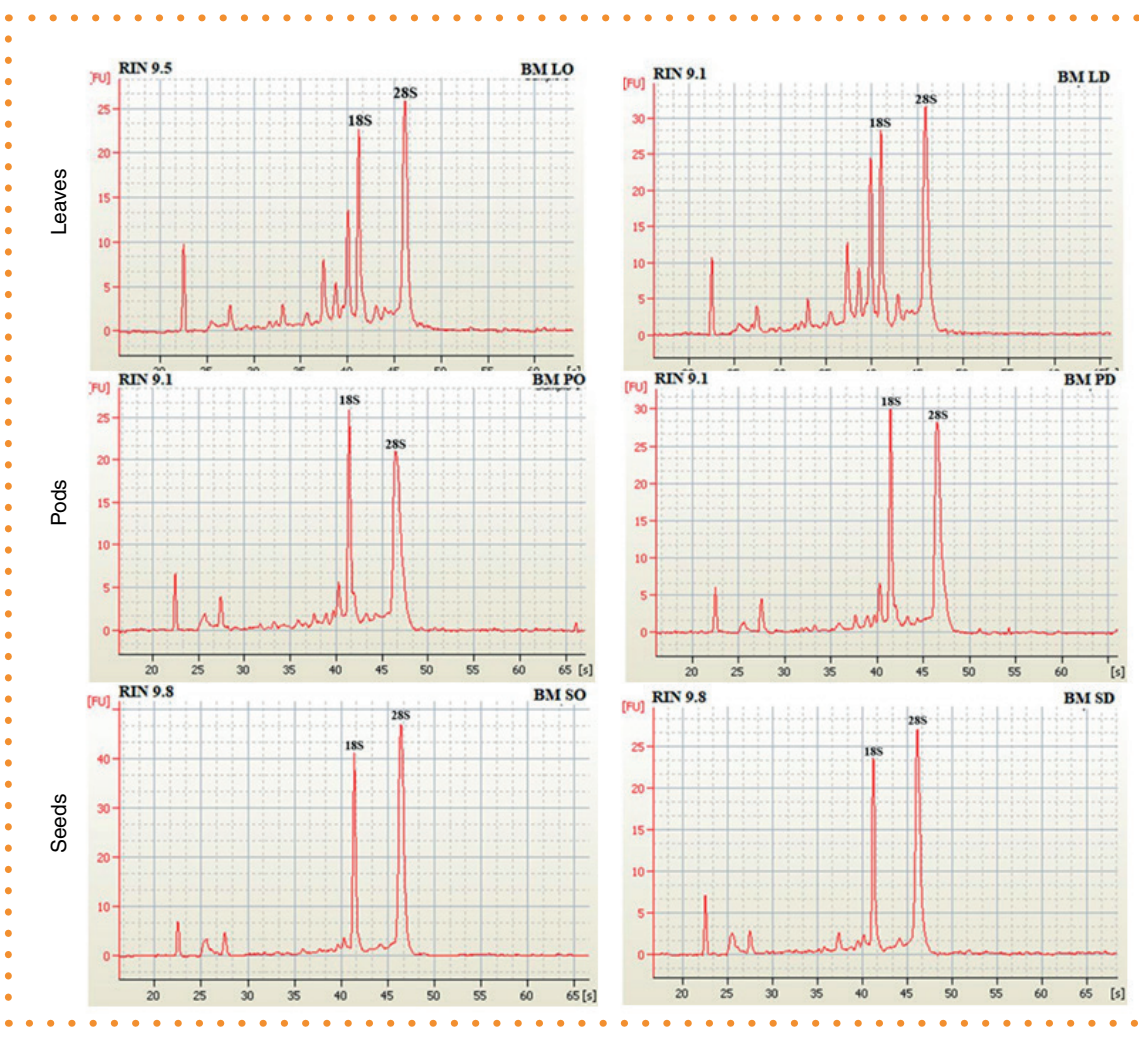

Figure 3. Chromatograms obtained from microcapillary electrophoresis using Bionalyzer 2100 for the separation of RNA samples extracted from different organs of Bayo Madero (BM) cultivar. All electropherograms obtained showed high-quality RNA (RIN above 9), and a high 28S /18S rRNA ratio. Similar results were obtained from the Pinto Saltillo cultivar. In addition to the $28 \mathrm{~S}$ and $18 \mathrm{~S}$ RNAs, represented by the highest peaks, samples from leaves also contain RNAs from chloroplasts (16S and 23S) and from mitochondria (23S), corresponding to the lower peaks.

BMLO: Leaves, optimal irrigation; BMLD: Leaves, drought; BMPO: Pods, optimal irrigation; BMPD: Pods, drought; BMSO: Seeds, optimal irrigation; BMSD: Seeds, drought; RIN: RNA ingerity number.

\section{- AUTHOR CONTRIBUTIONS}

Experiments were conceived and designed by AAM and IGL. Analysis and interpretation of results were performed by AAM, IGL and AAC. Writing of the manuscript was by AAM and AAC.

\section{FINANCIAL \& COMPETING INTERESTS DISCLOSURE}

This work was in part supported by the Comisión Nacional para la Biodiversidad (CONABIO-GRP10184). AAM received a postdoctoral fellowship from CONABIO grant. IGL is a PhD student of the Biomedical Sciences Program of the Universidad Nacional Autónoma de México (UNAM), and is recipient of a PhD fellowship from the Consejo Nacional de Ciencia y Tecnología (CONACyT-México). The authors have no other relevant affiliations or financial involvement with any organization or entity with a financial interest in or financial conflict with the subject matter or materials

\section{REFERENCES}

1. Graham $\mathrm{PH}$, Vance $\mathrm{CP}$. Legumes: importance and constraints to greater use. Plant. Physiol. 131, 872-877 (2003).

2. Fleige $S, P f a f f I M W$. RNA integrity and the effect on the real-time qRT-PCR performance. Mol. Aspects Med. 27, 126-139 (2006)

3. Lewis R. Kits take the trickiness out of RNA isolation, purification. Scientist 11, 16-17 (1997).

4. Schneiderbauer A, Sandermann H, Ernst D. Isolation of functional RNA from plant tissues rich in phenolic compounds. Anal. Biochem. 197, 91-95 (1991).

5. John ME. An efficient method for isolation of RNA and DNA from plants containing polyphenolics. Nucleic Acids Res. 20, 2381 (1992).

6. Ainsworth C. Isolation of RNA from floral tissue of Rumex acetosa (Sorrel). Plant Mol. Biol. Rep. 12, 198-203 (1994).

7. Lewinsohn E, Steele CL, Croteau R. Simple isolation of functional RNA from woody stems of gymnosperms. Plant Mol. Biol. Rep. 12, 20-25 (1994).

8. Schultz DJ, Craig R, Cox-Foster DL et al. RNA isolation from recalcitrant plant tissue. Plant Mol. Biol. Rep. 12 310-316 (1994)

9. Claros MG, Cinovas FM. Rapid high quality RNA preparation from pine seedlings. Plant Mol. Biol. Rep. 16, 9-18 (1998)

10. Geuna $E$, Hartings $H$, Scienza A. A new method for rapid extraction of high quality RNA from recalcitrant tissue of grapevine. Plant Mol. Biol. Rep. 16, 61-67 (1998).

11. Kiefer E, Heller W, Ernst D. A simple and efficient protocol for isolation of functional RNA from plant tissues rich in secondary metabolites. Plant Mol. Biol. Rep. 18, 33-39 (2000).

12. Vicient $\mathrm{CM}$, Delseny M. Isolation of total RNA from Arabidopsis thaliana seeds. Anal. Biochem. 268, 412-413 (1999).

13. Cuellar-Ortiz SM, De La Paz Arrieta-Montiel M, Acosta-Gallegos JA et al. Relationship between carbohydrate partitioning and drought resistance in common bean. Plant Cell Environ. 31, 1399-1409 (2008)

14. Rosales MA, Ocampo E, Rodríguez-Valentín R et al. Physiological analysis of common bean (Phaseolus vulgaris $\mathrm{L}$.) cultivars uncovers characteristics related to vulgaris $\mathrm{L}$.) Cultivars uncovers characteristics related to 24-34 (2012).

15. Kirkham MB. Chapter 10: Field capacity, wilting point, available water, and the non-limiting water range. In: Principles of Soil and Plant Water Relations (Second Edition). Academic Press. 153-170 (2014).

16. Mini Hot Phenol Protocol www.mylne.org/files/Mini Hot_Phenol.pdf

17. Tesniere C, Vayda ME. Method for isolation of high-quality RNA from grape berry tissues without contaminating tannins or carbohydrates. Plant Mol. Biol. Rep. 9 242-251 (1991)

discussed in the manuscript apart from those disclosed.

No writing assistance was utilized in the production of this manuscript.

\section{ACKNOWLEDGMENTS}

We are grateful to Dr Caspar Chater for critically reviewing this manuscript.

\section{OPEN ACCESS}

This work is licensed under the AttributionNonCommercial-NoDerivatives 4.0 Unported License. To view a copy of this license, visit http://creativecommons.org/licenses/ by-nc-nd/4.0/

\section{SUPPLEMENTARY DATA}

A supplementary protocol accompanies this paper. To view the supplementary data that accompany this paper please visit the journal website at: www.future-science.com/doi/ suppl/10.2144/btn-2018-0129

18. Loomis WD. Overcoming problems of phenolics and quinones in the isolation of plant enzymes and organelles. Meth. Enzymol. 31, 528-544 (1974).

19. Liao Z, Chen M, Guo L et al. Rapid isolation of high quality total RNA from Taxus and Ginkgo. Prep. Biochem. Biotechnol. 34, 209-214 (2014).

20. NanoDrop manual: https://bioscibatzerlab.biology.lsu. edu/Genomics/documentation/3130_NanoDrop_tips.pd

21. Sambrook J, Fritsch EF, Maniatis T. Molecular Cloning: a Laboratory Manual, 2nd Ed. Cold Spring Harbor Laboratory Press, NY, USA (1989).

22. Manchester KL. Use of UV methods for measurement of protein and nucleic acid concentrations. Biotechniques 20, 968-970 (1996)

23. Mueller $\mathrm{O}$, Lightfoot $\mathrm{S}$, Schroeder A. RNA integrity number (RIN) - standardization of RNA quality control. Agilent Application Note. Publication 5989-1165EN. 1-8 (2004) 